\title{
Floros, C. (2020). El hombre, el amor y la música (traducción de Nieves Pascual León). Salamanca: Ediciones Universidad de Salamanca, 252 pp. ISBN: 978-84-1311-274
}

"A medida que se profundiza en la historia del pensamiento, más claramente cristalizan tres puntos de referencia fundamentales: Dios, el universo y el hombre" (p. 31). Con esta certera afirmación, el Dr. Constantin Floros, Catedrático emérito de Musicología de la Universidad de Hamburgo, uno de los grandes referentes de la musicología internacional, invita al lector a profundizar en su volumen Der Mensch, die Liebe und die Musik como parte del "Prólogo" de la primera edición, alemana (Zurich/Hamburg: Arche Verlag), del año 2010. Afortunadamente para los lectores hispanohablantes, acaba de publicarse la traducción al castellano de este El hombre, el amor y la música, a cargo de la Dra. Nieves Pascual León, Catedrática de Musicología del Conservatorio Superior de Música "Joaquín Rodrigo" de Valencia.

La doctora Pascual León, especialista en música del siglo XVIII, tras su traducción crítica al español del Versuch einer gründlichen Violinschule de Leopoldo Mozart (Sant Cugat: Arpegio, 2013) y el interesante volumen La interpretación musical en torno a 1750: estudio crítico de los principales tratados instrumentales de la época a partir de los contenidos expuestos en la Violinschule de Leopold Mozart (Salamanca: Ediciones Universidad de Salamanca, 2016) -entre otros trabajos-, en esta ocasión, ofrece al lector un volumen donde, a través de una traducción rigurosa y contrastada, refleja el complejo pensamiento de Floros, gestado a lo largo de su extensa carrera académica y ya plasmado en otros volúmenes de referencia, como sus monografías Mozart-Studien I. Zu Mozarts Sinfonik, Opern- und Kirchenmusik (Wiesbaden: Breitkopf, 1979), Johannes Brahms. "Frei, aber einsam". Ein Leben für eine poetische Musike (Zürich/Hamburg: Arche, 1997) o Anton Bruckner. Persönlichkeit und Werk (Hamburg: Europäische Verlagsanstalt, 2004), entre otras.

La edición española El hombre, el amor y la música protagonista de esta reseña comienza, a modo de presentación, con las contribuciones del Dr. Antonio Ezquerro (Investigador Científico del CSIC,), el Dr. Joan Grimalt (Docente de la ESMUC) y el Dr. Paulino Capdepón (Catedrático de Musicología de la UCLM y Director del CIDoM), lo que da cuenta de la trascendencia del volumen y del apoyo institucional de la propia publicación, sirviendo, además, para ofrecer una semblanza en torno a la vida y obra de Constantin Floros. Tras el "Prólogo del autor a la edición en castellano" y una nota de la traductora, el volumen recoge, de forma fiel, los contenidos de Der Mensch, die Liebe und die 
Musik, conformados por el "Prólogo", dos partes, un epílogo y una extensa y excelsa bibliografía que denota la sabiduría de su autor.

Su primera parte, "«El hombre es la medida de todas las cosas». Música humana”, significa un acercamiento al concepto de la disciplina musical en torno al ser humano. Así, en el primer capítulo “¿Qué es la música?”, Floros ya evidencia la tesis principal del libro al afirmar que la música "es «producida» por los hombres (compuesta, improvisada e interpretada) y es definida para los hombres" (p. 40). Defendiendo en todo momento la relevancia del análisis semántico, conjuntamente al análisis estructural y a otro tipo de aproximaciones, el musicólogo profundiza en torno a esta manifestación artística a partir de su efecto sobre los hombres. Eso se puede comprobar en el segundo capítulo, "El frecuentemente invocado poder de la música", vertebrado en torno al mito de Orfeo para explicar el efecto de la música sobre las personas y cómo "puede incluso vencer la muerte y evitarla" (p. 50), en el capítulo 3, "El amor y el odio: los afectos más violentos", en torno a la teoría de los afectos -reflejo de las pasiones del alma, especialmente el amor, el odio o los celos- aplicada a la música de los siglos XVII y XVIII hasta Mozart porque "puede calificarse como humana, puesto que, en gran medida, es expresión de los afectos, pasiones, sentimientos y sensaciones" (pp. 59-60), y en el capítulo 4, "Alegría y melancolía", donde no solo se profundiza en vestigios representativos del legado de Haendel, C. P. E. Bach o Beethoven, sino donde se integran referencias plásticas, lo que suscribe la amplia e interdisciplinar cultura del autor.

En el capítulo 5, "Retratos musicales, el Dr. Floros ilustra el modo en que algunos autores son capaces de representar personas a través de los sonidos musicales, tomando como punto de partida "Samuel Goldenberg y Schmuyle" de Cuadros para una exposición de Mussorgsky, varias obras para tecla de Couperin o la Sonata "Cannabich" de Mozart. Por su parte, el sexto capítulo, “"Una música que concierne a toda la humanidad». Karl Amadeus Hartmann y su Sexta sinfonía" significa una aproximación al legado de este sinfonista alemán -cuyas obras no se interpretaron durante el régimen nazi-, mientras que el capítulo 7, "Música y astrología. Los Planetas de Gustav Holst", demuestra la incidencia de la teoría de las esferas ya formulada en la Antigüedad en torno a un compositor contemporáneo. Esta primera parte concluye con un octavo capítulo que, bajo el título de "Fenómenos multiculturales en la Nueva Música", demuestra que la música puede ser comprendida como un lenguaje universal, siendo éste una capacidad exclusivamente humana. En este último caso, el autor demuestra que, de la misma forma que el mundo se transformó tras la II Guerra Mundial, también la música experimentó cambios, como queda ilustrado a través de un contexto representado en torno a Olivier Messiaen, Karlheinz Stockhausen, Isang Yun y György Kurtág.

Mientras que la primera parte se centra en la trascendencia significativa, espiritual y social de la música, la segunda, expuesta bajo el título "«Y el misterio del amor es mayor que el misterio de la muerte». La música como lenguaje sonoro del amor”, presenta, desde una mirada eminentemente germanófila, una profundización sobre la percepción del amor a través de la composición musical. Así, mientras el primer capítulo se dedica a la "Sensualidad y amor. El «espíritu de la música»", el segundo de ellos, "Facetas del amor en el teatro musical mozartiano", profundiza en el legado operístico del compositor 
salzburgués -con especial interés en El rapto en el serrallo, Las bodas de Fígaro, Don Giovanni y La flauta mágica-. Por su parte, el capítulo 3, "La delicada música instrumental de Mozart y Beethoven. Movimientos de concierto y sinfonía como escenas de amor imaginarias”, lleva a cabo un estudio donde lo analítico y la teoría de la recepción se dan la mano en torno al Concierto para fagot en Si bemol mayor KV 191, el Concierto para violín en Sol mayor KV 216, el Concierto para piano en Si bemol mayor KV 238, Concierto para piano en Mi bemol mayor KV 271, Concierto para flauta en Sol mayor KV 313, Concierto para piano en La mayor KV 414, Concierto para piano en Fa mayor KV 413, Concierto para piano en Mi bemol mayor KV 449, el Concierto para piano en Do mayor KV 467 y la Sinfonía Júpiter en Do mayor KV 551 de Mozart, llevando a cabo una analogía entre estas composiciones instrumentales y otros vestigios operísticos. Del mismo modo, el autor profundiza en torno al concepto de música sentimental con especial atención al "Largo" del Concierto para piano op. 37 de Beethoven. El discurso continúa en el contexto alemán. Así, el capítulo 4 de la segunda parte, “"Un profundo lamento por ti». Mensajes secretos en la música para piano de Robert Schumann", presenta la tesis de que la música para piano temprana de Schumann tiene un importante componente autobiográfico, especialmente plasmando la historia de amor entre Robert y Clara Schumann a través del legado del compositor en obras anteriores a su matrimonio, como la Davidsbündlertänz̧e Op. 6, entre otras.

Los cuatro últimos capítulos están dedicados a Wagner en torno a "El amor «redentor del mundo». La gran utopía de Richard Wagner", "La afinidad del amor y la muerte. Tristán e Isolda", "Psicopatología del amor. Salomé” -éste con especial relevancia en torno a los estudios de género, que gozan de especial actualidad en los últimos años- y "Desengaño amoroso", correspondientes con los capítulos quinto, sexto, séptimo y octavo, respectivamente. Esta circunstancia demuestra la riqueza musical y semántica del compositor alemán, pero también el profundo conocimiento del doctor Floros.

Podemos afirmar que el volumen aquí reseñado es una novedad editorial de gran profundidad, cuya principal aportación radica en invitar al lector a reflexionar sobre qué es la música y los efectos y emociones que despierta en torno al ser humano, que es, al fin y al cabo, el protagonista del hecho musical y de la creación. Asimismo, conviene apuntar que el hecho de que esta edición castellana presente, a diferencia de la original, las notas a pie de página supone un gran acierto, pues permite al lector profundizar de una forma más cómoda en aquellos contenidos de ampliación y en las correspondientes referencias bibliográficas. En definitiva, El hombre, el amor y la música de Constantin Floros, a través de la traducción de la doctora Nieves Pascual León, se caracteriza, además de lo expuesto, por el profundo pensamiento de Floros y la rigurosidad respecto de su primera edición, motivos, entre otros, por los que será considerado como un volumen de referencia en los estudios musicológicos en castellano.

\section{Virginia Sánchez Rodríguez}

Universidad de Castilla-La Mancha

Centro de Investigación y Documentación Musical (CIDoM)-Unidad Asociada al CSIC

ORCID iD: https://orcid.org/0000-0001-8071-2937 